Bioscientia Medicina: Journal of Biomedicine \& Translational Research

Journal Homepage: www.bioscmed.com

\title{
Correlation of Prolonged Total Ischemic Time with Body Mass Index in Kidney Transplant: A Single Center Report
}

\section{Eriawan Agung Nugroho' ${ }^{1}$, Erwin Wibowo², Prathita Amanda Aryani2 ${ }^{*}$}

${ }^{1}$ Division of Urology, Department of Surgery, Dr Kariadi General Hospital, Medical Faculty Diponegoro University, Semarang Indonesia

${ }^{2}$ Resident of General Surgery, Dr Kariadi General Hospital, Medical Faculty Diponegoro University, Semarang Indonesia

\section{A R T I C L E I N F O}

\section{Keywords:}

Total ischemic time

Kidney Transplantation

Body Mass Index

*Corresponding author:

Prathita Amanda Aryani

\section{E-mail address:}

\section{thitaamanda@gmail.com}

All authors have reviewed and approved the final version of the manuscript.

\begin{abstract}
A B S T R A C T
Background: Chronic kidney disease (CKD) is a rising health concern worldwide, especially in Indonesia. The treatment of choice for end-stage renal disease is Kidney Transplantation. 1 Numerous studies showed that prolonged total ischemic ischemic time may cause hypoxia of the graft tissue and increased risk of ischemia and reperfusion injury (IRI) and delayed graft function (DGF).2 Body mass index of kidney transplant recipients may cause prolonged duration of the procedure, as well as prolonged total ischemic time. This study aimed to determine the correlation between prolonged total ischemic time with body mass index. Methods: This was an observational and cross-sectional analysis at Kariadi General Hospital Semarang involving patients who underwent kidney transplantation from January 2016 to December 2019. The total ischemic time was recorded intraoperatively. The Body Mass Index data were provided by medical records. The program used to statistically analyze the data was SPSS 23.0, and Spearman was used for hypothesis testing. Results: This study included 25 kidney transplant recipients. The mean total ischemic time was $43,27 \pm 6,63$ minutes. There was a significant positive correlation between prolonged ischemic time and body mass index $(r=0,506 ; p=0,010)$. Conclusion: Prolonged total ischemic time was positively correlated with increased body mass index and these results are statistically significant.
\end{abstract}

https://doi.org/10.32539/bsm.v5i11.367

\section{Introduction}

One of the increasing global problems in Indonesia as well as in the world is chronic kidney disease (CKD). There are a lot of treatment modalities in chronic kidney disease, one of them is kidney transplantation which is the treatment of choice in end-stage renal disease. ${ }^{1}$ Many factors affect kidney transplantation success, as described by Novianti et al (2019) one of them is the intraoperative factor. No blood flow to the kidney graft will cause a condition of ischemic time, which can be occurred during surgery of kidney graft transplantation. As shown in many studies the risk of ischemia and reperfusion injury (IRI) and delayed graft function (DGF) can increase with long ischemic time duration. Failure of renal transplant to function immediately with the need for dialysis in the first posttransplantation week define delayed graft function or known as DGF. ${ }^{2}$ There are three potential periods of ischemic injury during a kidney graft transplantation surgery as stated by Vinson et al (2018), first is the period before organ retrieval in the donor's body, or know as "first warm ischemia time". The second period occurred when transported donor organ to the recipient in a cold solution, which is defined as cold ischemia time (CIT). The last period occurred during reanastomosis in the recipient's body, the process in which kidney graft was taken out of cooling and reperfused by the recipient's blood, this period is known as second warm ischemia time (WIT). ${ }^{3}$ Total 
ischemic time can be prolonged by many factors. This study aims to determined the correlation of prolonged total ischemic time with body mass index.

\section{Material and Methods}

An observational study with a cross-sectional approach was conducted with data that was collected from the medical record of patients who underwent kidney transplantation operations from January 2014 up to December 2018 in Kariadi General Hospital, Semarang. Patients with renal failure who undergone kidney transplantation operation in Kariadi General Hospital, Semarang from January 2014 up to December 2018 are the population of this study. Twenty five patients registered and met the inclusion criteria. Age, sex, body weight, body mass index (BMI), donor relationship, date of operation, hospital discharge date (length of stay) were extracted as data from the medical record. The time of the renal artery or aortic clamp is disrupted up to renal artery clamps are removed at the recipient defined the total ischemic time which was measured in hours. ${ }^{4,5}$ There is a correlation between prolonged total ischemic time with body mass index as the total ischemic time was recorded. Tables and boxplots are used to present descriptive data in this study. Spearman test was performed using SPSS version 23.0 and the result is considered significant with $\mathrm{p}<0.05$. ROC curve then made to show the result of diagnostic test from CIT with body mass index, the result was shown in sensitivity and 1 - specificity.

\section{Results}

Data were obtained from medical records of patients who underwent kidney transplantation from January 2014 to December 2018 at Dr. Kariadi General Hospital Semarang, Indonesia. The data shows that there were 25 patients. Mean age is 33,32 $\pm 11,26$ year (range 1550). There were 25 subjects, among them were 18 men and 7 women. The total number of subjects who received transplantation from the family-related donor were 18 patients and 7 patients received transplantation from a non-family related donor. Mean ischemic time of 25 subjects was 43,27 $\pm 6,63 \mathrm{~min}$ (range 35,22 - 58,85). The mean length of hospitalization was $13,92 \pm 3,69$ days (range 10-20). From the results of research conducted on 25 subjects, we found that the body mass index average was 21,14 $\pm 4,15$. (range $13,8-32,2$ ) (Table 1). From the analysis using the Pearson correlation test and Wilcoxon signed rank test, it was determined that there was a correlation between prolonged total ischemic time and body mass index increase from $r=0,506(p=0,010)$ (Table 2).

We compared Table 2 as additional variables in this study using Spearman correlation, comparing the correlation between patient age and total ischemic time with $r=-0,130$ with an insignificant impression, where the $\mathrm{p}$-value was significant if $\mathrm{p}<0.05$. The normality test used to compare total ischemic time based on sex was Shapiro - Wilk test and the distribution of normal blood for female subjects was obtained, whereas on male subjects we used Mann - Whitney test where the correlation was statistically normal. $(\mathrm{p}=0.515)$.

Table 1. Average characteristic data of the patients who underwent kidney transplantation

\begin{tabular}{|l|c|c|c|c|}
\hline \multicolumn{1}{|c|}{ Variable } & F & \% & Mean \pm SD & Median (min - max) \\
\hline Gender & & & & \\
\hline Male & 18 & 72,0 & & \\
\hline Female & 7 & 28,0 & & $31(15-50)$ \\
\hline Age & & & $33,32 \pm 11,26$ & $14(10-20)$ \\
\hline Length of hospitalization & & & $13,92 \pm 3,69$ & $42,27(35,22-58,85)$ \\
\hline Total ischemic & & & $43,27 \pm 6,63$ & $20,8(13,8-32,2)$ \\
\hline Body mass index & & & $21,14 \pm 4,15$ & \\
\hline
\end{tabular}


Table 2. Correlation between age and body mass index with total ischemic time (Pearson correlation test)

\begin{tabular}{|c|c|c|c|}
\hline \multirow{2}{*}{ Variable } & \multicolumn{2}{|c|}{ Total Ischemic time } & \multirow{2}{*}{ Description } \\
\cline { 2 - 4 } & $\mathbf{p}$ & $\mathbf{r}$ & insignificant \\
\hline Age & 0,536 & $-0,130$ & Significant, positive, moderate \\
\hline Body mass index & 0,010 & 0,506 & \\
\hline
\end{tabular}

Figure 1. Comparison of total ischemic time between male and female

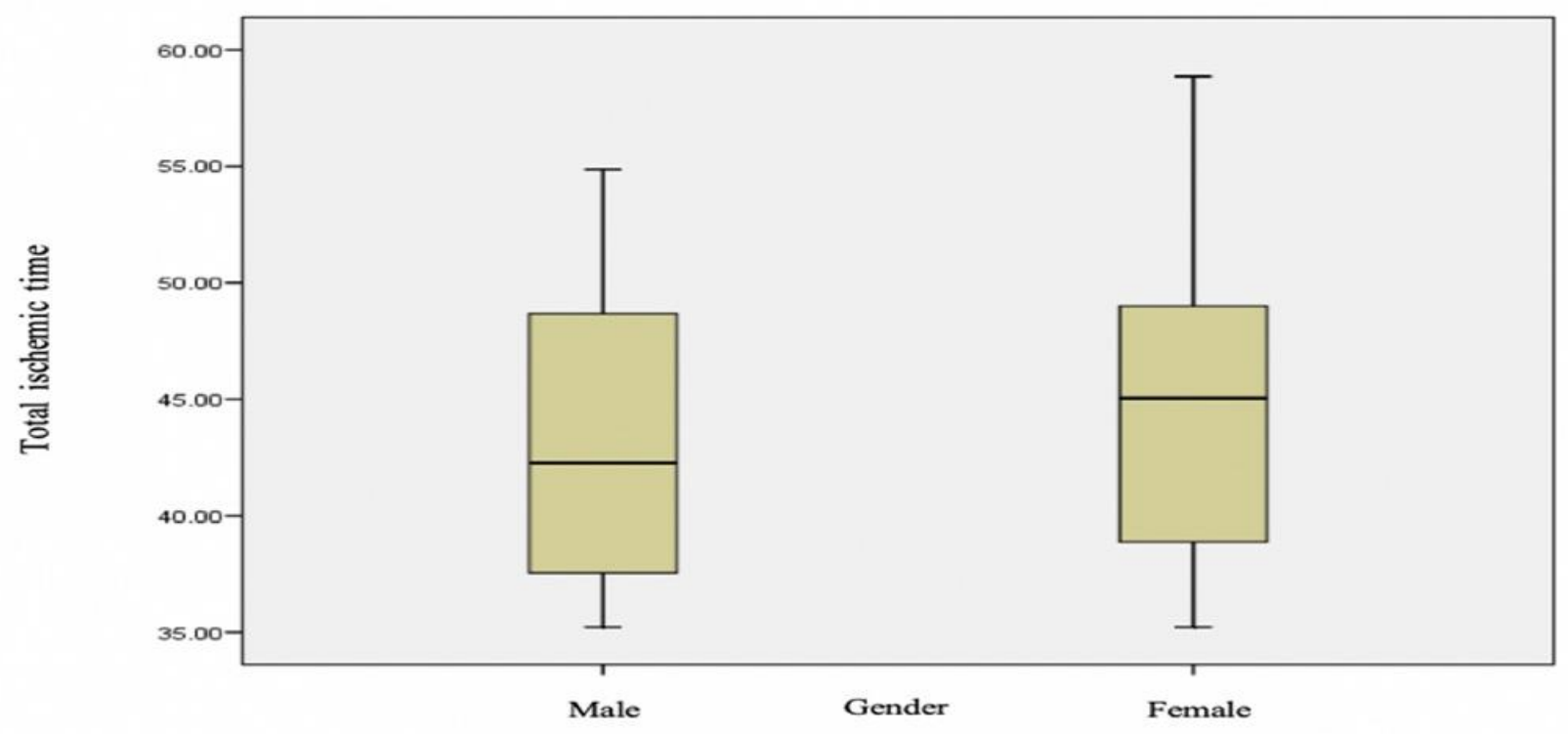

Figure 2. ROC curve of CIT with BMI

ROC Curve

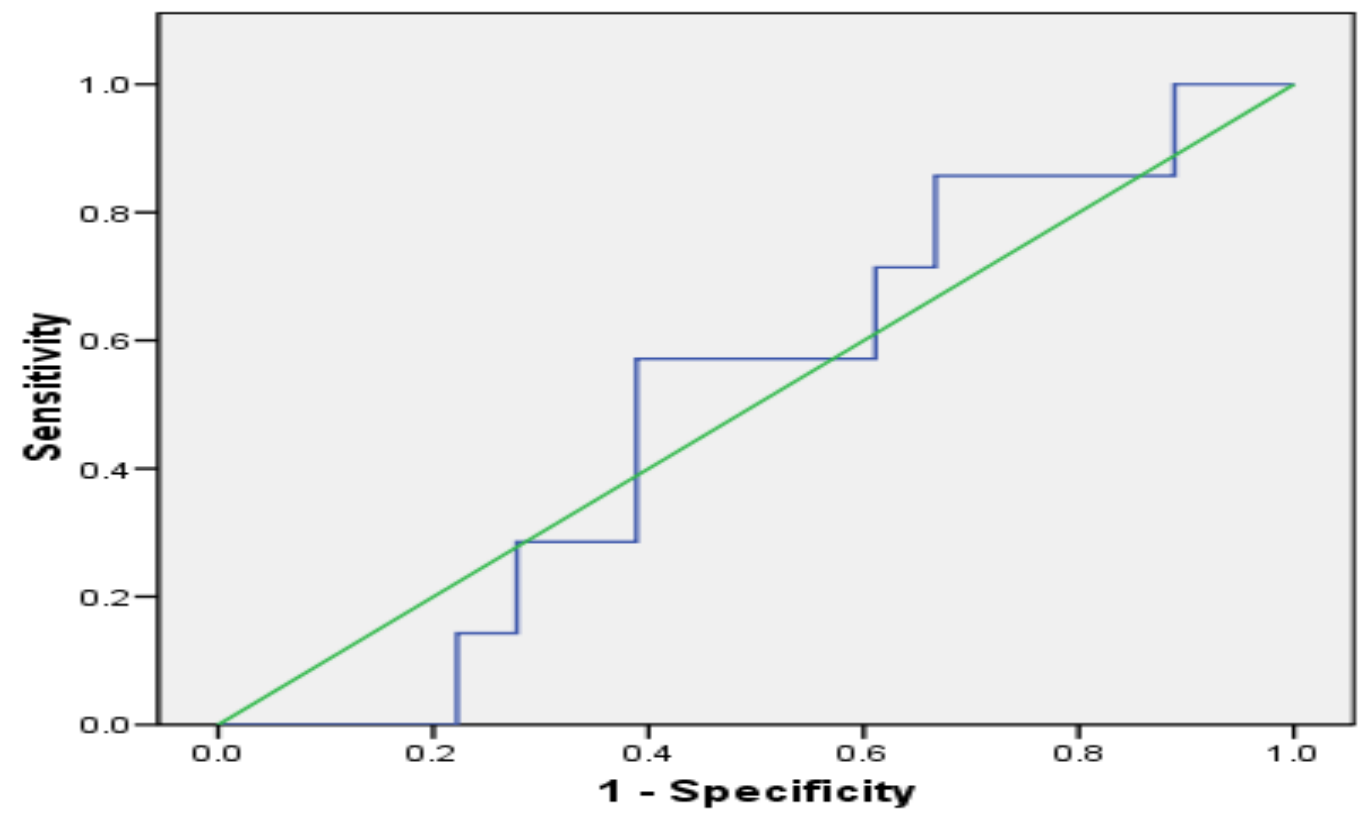


Table 3. Diagnostic table

\begin{tabular}{|c|c|c|c|c|c|c|c|c|c|}
\hline \multirow{2}{*}{ Variable } & \multirow{2}{*}{ Category } & \multicolumn{2}{|c|}{ CIT } & \multirow{2}{*}{$\begin{array}{c}\text { Sens. } \\
(\%)\end{array}$} & \multirow{2}{*}{$\begin{array}{c}\text { Spe. } \\
(\%)\end{array}$} & \multirow{2}{*}{$\begin{array}{l}\text { PPV } \\
\text { (\%) }\end{array}$} & \multirow{2}{*}{$\begin{array}{l}\text { NPV } \\
(\%)\end{array}$} & \multirow{2}{*}{$\begin{array}{c}\text { Acc. } \\
(\%)\end{array}$} & \multirow{2}{*}{$\mathbf{p}$} \\
\hline & & $\geq 48$ & $<48$ & & & & & & \\
\hline \multirow{2}{*}{ BMI } & $\geq 20,89$ & 4 & 8 & \multirow{2}{*}{57,14} & \multirow{2}{*}{55,56} & \multirow{2}{*}{33,33} & \multirow{2}{*}{76,92} & \multirow{2}{*}{56,00} & \multirow{2}{*}{0,450} \\
\hline & $<20,89$ & 3 & 10 & & & & & & \\
\hline
\end{tabular}

\section{Discussion}

\section{Correlation between Prolonged Total Ischemic} Time and Body Mass Index

There is an important relationship between increased body mass index of recipients with kidney transplantation. Unlike in people who have a normal body mass index, an increase in the body mass index to the effects of prolonged cold ischemia and subsequent ischemic reperfusion injury, an intense inflammatory response could further compromise these susceptible donor grafts. ${ }^{4}$ The body mass index of the recipient affects the length of total ischemic time because it potentially causes a long operation time when freeing the renal arteries, renal veins, and ureters. Furthermore, long operation time will eventually affect the length of stay.

Total ischemic time was defined as the time the initiation of interruption of the donor renal artery to the time of arterial clamp release of the recipient in hours. ${ }^{6}$ Total ischemic time is the sum of warm ischemic time (WIT) and cold ischemic time (CIT). ${ }^{5}$ Many studies have shown that CIT is an independent risk factor for delay graft function (DGF), that is elongation of CIT is associated with increased DGF. 6 In this study, the statistical analysis between prolonged of the total ischemic time with body mass index using the Spearman were found significant.

Our study showed a significant correlation between body mass index with total ischemic time $(\mathrm{p}=0.010)$. This study yielded the same results as that of Molnar et al, where it was stated that patients who were overweight (BMI 25.0 - 29.9), mildly obese (BMI 30 34.9), and moderate-severely obese (BMI > 35.0) had a higher risk of developing DGF $30 \%, 42 \%$, and $118 \%$ respectively than patients with normal body mass index $(\mathrm{p}<0.05) .7$ This study was also in accordance with the research conducted by Naik et al, which concluded that body mass index (BMI) is an independent predictor of DCGF. ${ }^{8}$ In another study with a similar topic conducted by Arshad et al, it concluded that prevalence of DGF increased along with an increase in body mass index $(\mathrm{p}<0.001)$ with an odds ratio of 1.38 (95\% CI: $1.16-1.63)$ in the $>35.0$ and 18.5 - 25.0 groups. ${ }^{9}$ However, this study also mentioned that there was no correlation between body mass index and serum creatinine level during the 12 months following the transplantation. Another conclusion produced from this study was that there was a significant correlation between an increase in donor body mass index (BMI) and warm ischemia time (WIT) with a mean of $4,6 \%(p=0.043)$ and $5.2 \%(P=0.013)$ per increase of $10.0 \mathrm{~kg} / \mathrm{m}^{2}$. In a study conducted by Molnar et al, it was mentioned that when compared with patients with pre-transplant body mass index value of $22-24.9 \mathrm{~kg} / \mathrm{m}^{2}$, patients with excess body mass index (25.0 - 29.0), mild obesity (30 - 34.9), and moderate-severe obesity ( $>35 \mathrm{~kg} / \mathrm{m}^{2}$ or more) had a higher risk of developing DGF with an odds ratio of $1.30,14.2$, and 2.18 respectively. ${ }^{7}$

The globally recognized gold standard treatment of ESRD is kidney transplantation. However, kidney transplantation possesses some complications, one of them is delayed graft function, which is majorly affected by a longer ischemic time during surgery. ${ }^{2}$ However, proper functioning of the graft is essential for patients to re-establish body homeostasis so that this transplant can be useful for the patients. The injury during low oxygen and the restoration of oxygen had been proposed to induce ischemia-reperfusion injury (IRI). ${ }^{2}$

Despite no differences has been reported in terms of renal function, it is important to note that there are studies that reported the consequences of a long ischemic time. Many growing studies discussed this 
issue regardless of its significance in the statistical calculation. Still, the descriptive analysis showed a negative effect of longer total ischemic time on renal function. A more comprehensive analysis of this effect is needed with further research. ${ }^{2}$

\section{Conclusion}

There is a statistically significant positive correlation between prolonged total ischemic time with increased body mass index. This research is hoped can provide an overview to help shorten the ischemic time during operation.

\section{References}

1. Supit T, Nugroho EA, Santosa A, Soedarso MA, Daniswara N, Addin SR. Kidney transplantation in Indonesia: An update. Asian J Urol 2019. https://doi.org/10.1016/j.ajur.2019.02.003.

2. Novianti PA, Duarsa GWK, Aditya GA, Oka AAG, Santosa KB, Yudiana IW, et al. Correlation of total ischemic time to creatinine serum level and resistive index value in kidney transplant. Neurol Spinale Med Chir 2020;3:26-31.

https://doi.org/10.36444/nsmc.v3i2.109.

3. Vinson AJ, Rose C, Kiberd BA, Odutayo A, Kim SJ, Alwayn I, et al. Factors associated with prolonged warm ischemia time among deceased donor kidney transplant recipients. Transplant Direct 2018. https:/ /doi.org/10.1097/TXD.000000000000 0781.

4. Nugroho EA, Kamar MA, Junita D. International Journal of Science and
Engineering ( IJSE ) The Correlation Between

Total Ischemic Time with Length of Hospitalization in Kidney Transplantation: A Single Centre Report 2019;13:28-30.

5. Nugroho EA, Hidayat A, Hidayat AT. Correlation of Warm and Cold Ischemic Time to Graft Function in Kidney Transplant: A Single Centre Report. Open Urol Nephrol J 2019. https://doi.org/10.2174/1874303x01912010 066.

6. Nugroho EA, Kamar MA, Santosa A, Daniswara N, Addin SR. The Correlation Between Total Ischemic Time on Kidney Transplantation with the Length of Hospitalization: A Single Center Report. Medica Hosp J Clin Med 2020. https://doi.org/10.36408/mhjcm.v7i1.426.

7. Molnar MZ, Kovesdy CP, Mucsi I, Bunnapradist S, Streja E, Krishnan M, et al. Higher recipient body mass index is associated with post-transplant delayed kidney graft function. Kidney Int 2011. https://doi.org/10.1038/ki.2011.114.

8. Naik AS, Zhong Y, Parasuraman R, Doshi M, Norman S, Lu Y, et al. The temporal and longterm impact of donor body mass index on recipient outcomes after kidney transplantation - a retrospective study. Transpl Int 2020. https://doi.org/10.1111/tri.13505.

9. Arshad A, Hodson J, Chappelow I, Inston NG, Ready AR, Nath J, et al. The impact of donor body mass index on outcomes after deceased kidney transplantation - a national population-cohort study. Transpl Int 2018. https://doi.org/10.1111/tri.13263. 